\title{
Cranial morphology, systematics and succession of beavers from the middle Miocene Valentine Formation of Nebraska, USA
}

\author{
William W. Korth \\ Acta Palaeontologica Polonica 53 (2), 2008: 169-182 doi:http://dx.doi.org/10.4202/app.2008.0201
}

Previously, it was believed that there was a dramatic turn-over in the fauna of beavers (Rodentia, Castoridae) from the Barstovian to the Clarendonian from Nebraska. Stratigraphically controlled collections of fossil castorids from the Valentine Formation, which cross this boundary, now indicate that a complete change in the castorid fauna did not occur, but instead a more gradual change and replacement of earlier taxa with more advanced taxa occurred. The range of Eucastor tortus and Monosaulax skinneri is extended from late Barstovian into the latest Barstovian Devil's Gulch Member and the range of the otherwise Clarendonian species of Prodipoides is extended downward into the late Barstovian Crookston Bridge Member.

The skulls of Monosaulax skinneri and Eucastor valentinensis are described in detail for the first time. The cranial morphology of M. skinneri is primitive for Castoroidini and that of E. valentinensis is specialized for tooth-digging behavior as in the Nothodipoidini. A new genus, Temperocastor, is proposed for E. valentinensis based on its primitive morphology of the cheek teeth and derived cranial morphology. Temperocastor represents the most primitive nothodipoidine.

Key words: Castoridae, faunal succession, Barstovian, Clarendonian, Valentine Formation

William W. Korth [wwkorth@frontiernet.net], Rochester Institute of Vertebrate Paleontology, 265 Carling Road Rochester, New York 14610, USA.

This is an open-access article distributed under the terms of the Creative Commons Attribution License (for details please see creativecommons.org), which permits unrestricted use, distribution, and reproduction in any medium, provided the original author and source are credited. 
